\title{
THREE DIMENSIONAL OBSERVATIONS AND MODELLING OF INTERGRANULAR STRESS CORROSION CRACKING IN AUSTENITIC STAINLESS STEEL.
}

\author{
T.J. Marrow, L. Babout, A.P. Jivkov, P. Wood, D. Engelberg, N. Stevens, P.J. Withers, \\ School of Materials, University of Manchester, UK and \\ R.C. Newman, Department of Chemical Engineering and Applied Chemistry, University \\ of Toronto, Canada
}

\section{Abstract}

Stress corrosion cracking is a life-limiting factor in many components of nuclear power plant in which failure of structural components presents a substantial hazard to both safety and economic performance. Uncertainties in the kinetics of short crack behaviour can have a strong influence on lifetime prediction, and arise due both to the complexity of the underlying mechanisms and to the difficulties of making experimental observations. This paper reports on an on-going research programme into the dynamics and morphology of intergranular stress corrosion cracking in austenitic stainless steels in simulated light water environments, which makes use of recent advances in high resolution X-ray microtomography. In particular in-situ, three dimensional X-ray tomographic images of intergranular stress corrosion crack nucleation and growth in sensitised austenitic stainless steel provide evidence for the development of crack bridging ligaments, caused by the resistance of non-sensitised special grain boundaries.

In parallel a simple grain bridging model, introduced to quantify the effect of crack bridging on crack development, has been assessed for thermo-mechanically processed microstructures via statically loaded room temperature simulant solution tests and as well as high temperature/pressure autoclave studies. Thermo-mechanical treatments have been used to modify the grain size, grain boundary character and triple junction distributions, with a consequent effect on crack behaviour. Preliminary threedimensional finite element models of intergranular crack propagation have been developed, with the aim of investigating the development of crack bridging and its effects on crack propagation and crack coalescence. 


\section{Introduction}

Stress corrosion cracking is a significant potential cause of failures in the nuclear power industry [1]. Cracking frequently nucleates from corrosion pits [2] and, depending on the material and environment, may be transgranular or intergranular in nature. The incubation period prior to the development of a critical crack nucleus depends on several factors [3]. These include the rate of pit/localized corrosion formation and growth, the transition from pit/localized corrosion to crack initiation, and the propagation of short cracks with a size comparable to the microstructure scale. Although models for these processes have been developed [3,4], the prediction of incubation periods remains uncertain due to the complex interaction between microstructure, environment and the mechanisms of localized corrosion and environmentally assisted cracking.

Resistance to intergranular corrosion and stress corrosion cracking can be affected by the distribution of grain boundary crystallographic character [5]. In particular, the grain boundary character may affect intergranular failure via its effect on solute concentrations [6] and precipitation [7]. Grain boundary engineering provides a means to improve the resistance to intergranular stress corrosion cracking by disrupting easy pathways through the microstructure [8]. The interactions between the crack and the microstructure are expected to be most significant when the crack is a short crack. However, very little is known about the behaviour of short stress corrosion cracks due to experimental difficulties in monitoring their nucleation and growth.

This paper describes how in-situ three-dimensional observations of the evolution of intergranular stress corrosion cracking in sensitised stainless steel have provided evidence for a crack bridging mechanism, by which the resistance to propagation of short stress corrosion cracks can be influenced by the grain boundary triple junction distribution. Experimental data for the effect of microstructure engineering on crack propagation resistance, and a comparison between the crack propagation in different environments is also presented. These observations provide the mechanistic basis for a new threedimensional computational model of short stress corrosion crack propagation, which will enable crack coalescence behaviour and the role of residual stress gradients to be investigated.

\section{Experimental Methods}

\section{Tomographic Imaging of SCC In 302 Stainless Steel}

In order to investigate the interaction between a propagating crack and the microstructure in-situ three dimensional observations of intergranular stress corrosion cracking were performed, using the ID19 X-ray microtomography beam line at the European Synchrotron Radiation Facility (ESRF), France. An annealed and fully sensitised 302 stainless steel wire (400 $\mu \mathrm{m}$ diameter) (Table 1) was tested in $0.15 \mathrm{M}$ potassium tetrathionate $\left(\mathrm{K}_{2} \mathrm{~S}_{4} \mathrm{O}_{6}\right)(\mathrm{pH} 2)$. Details of the technique $[9,10]$ and the experimental setup $[11,12]$ are described elsewhere with preliminary observations and analysis. In

essence, the wire was spot-welded to $3 \mathrm{~mm}$ diameter steel grub screws to form a tensile specimen, which was then lacquered to expose a gauge length of approximately $0.5 \mathrm{~mm}$. The specimen was tested under load (up to $200 \mathrm{MPa}$ ) in an environmental cell on the 
ID19 stage (Figure 1). Cracking was initiated by coupling the sample to a platinum working electrode for a few seconds to polarize the stainless steel wire anodically. Preliminary experiments demonstrated that cracking would then occur under open circuit conditions, and could be suspended for tomographic imaging by simultaneously reducing the load and coupling the stainless steel wire to a pure aluminium electrode to impose a cathodic polarisation. Cracking re-initiated when open circuit conditions were restored. Cracking occurred rapidly on re-application of the stress, which was progressively reduced as cracking was observed. The initiation of cracking and subsequent specimen failure due to coalescence was recorded in samples sensitised for 1 hour at $650^{\circ} \mathrm{C}$. X-ray imaging was undertaken at an energy of $30 \mathrm{keV}$. 1000 radiographs were taken in 90 minutes for each tomograph and were reconstructed by the back projection method. During the stress corrosion experiment 5 tomographic images were acquired.

\section{Stainless Test Microstructures}

To obtain characteristic microstructures to test predictive models, samples of type 304 austenitic stainless steel plate (Table 1) were thermo-mechanically processed, comprising uni-directional cold rolling to introduce $30 \%$ strain, followed by heat treatment in argon atmosphere at $900^{\circ} \mathrm{C}$ for 30 minutes with a subsequent water quench (900/30). This was compared with the as-received microstructure. Full details of the experiments, and the results of processing a wider range of microstructures, are reported elsewhere [20]. The basic microstructural features were quantified by electron backscatter diffraction (EBSD) with an HKL-EBSD system, interfaced to a Philips XL-30 FEG-SEM. Details of the data processing and analysis are reported elsewhere [14].

The information obtained by EBSD included the Grain Boundary Character (GBCD) and Triple Junction (TJD) distributions, using the Coincidence Site Lattice model (CSL) [15]. The low angle grain boundary (LAGB) threshold was set to $1.6^{\circ}$, with $15^{\circ}$ for high angle grain boundaries (HAGB), by applying Brandon's criterion $\left(\Delta \theta=15 \times \Sigma^{-1 / 2}\right)$ [22] for the maximum allowed deviation angle. The microstructural parameters for the two microstructures are summarised in Table 2 where it can be seen that considerable microstructural refinement and a measured reduction in the percentage of $\Sigma 3$ boundaries has been brought about by the (900/30) recrystallisation treatment.

\section{Room Temperature Crack Propagation Tests}

Crack propagation experiments were performed on the test microstructures to determine the effects of microstructure on crack propagation behaviour. Double-beam-bent specimens (DBB) (i.e. self-stressed four point bending) [24] were employed enabling us to investigate the extent of crack propagation as a function of applied static stress, test duration and microstructure. The sample size was approximately $200 \mathrm{~mm}$ x $20 \mathrm{~mm}$ x 1.5 $\mathrm{mm}$. The test electrolyte was aqueous $0.1 \mathrm{M}$ potassium tetrathionate solution, acidified with diluted sulphuric acid to $\mathrm{pH} 2.5$. All samples were fully sensitised at $650^{\circ} \mathrm{C}$ for 24 hours. After removal from the test environment and unloading, each specimen was strained in tension to open the intergranular cracks for observation. The cracks were found to lie within a log-normal population [20], and hence extreme value statistics, in the form of Gumbel distributions, were applied to evaluate the crack population $[25,26]$. 
This method allows the crack population to be described by measuring the longest crack in each sub-area of the sample.

\section{High Temperature Crack Propagation Tests}

High temperature stress corrosion crack propagation tests were conducted using the asreceived 304 stainless steel (Table 1) (fully sensitised at $650^{\circ} \mathrm{C}$ for 20 hours) to demonstrate that the crack bridging mechanism was not unique to the tetrathionate environment. A Cormet Testing Systems $10 \mathrm{kN}$ constant load autoclave comprising a manually operated constant load unit, internal palladium reference electrode and computer system was used with a $0.01 \mathrm{M} \mathrm{Na}_{2} \mathrm{SO}_{4}$ electrolyte at $250^{\circ} \mathrm{C}$ and a pressure of $40 \mathrm{bar}$. The tensile specimens, which had a gauge length of $20 \mathrm{~mm}$ and diameter $2.5 \mathrm{~mm}$, were polarised to $500 \mathrm{mV}$ above their rest potential under static load $(90 \%$ of room temperature yield stress) to promote stress corrosion cracking.

\section{D Observations of Intergranular Stress Corrosion Cracking}

The principal finding arising from this experiment was the demonstration of the formation and failure of crack bridging ligaments. For example, Figure 2 presents a sequence of longitudinal slices from the reconstructed tomographs at three different stages of stress corrosion cracking of the test wire, each slice taken at approximately the same location $(70 \mu \mathrm{m}$ from the sample centre). Two stress corrosion crack tips visible in these slices (identified as cracks 1 and 2 in Figure 2) have been studied. Discontinuity A corresponds to an arrested crack tip, while B and C are crack bridging ligaments which develop and then fail as the crack opening displacement increases. 3D isosurface rendering [13] of the tomographic data has been used to visualise the crack bridges.

Fractography of the sample after testing shows ductile features (e.g. Figure 3a), with geometries that indicate that they are defined by twin boundaries (Figure 3b). The twin boundaries are not sensitised, which is evidenced by the lack of intergranular cracking along the interface. EBSD analysis of a wide range of thermo-mechanically processed microstructures, processed with $30 \%$ strain and annealed at temperatures between $900^{\circ}$ and $1100^{\circ} \mathrm{C}$ for times between 2 minutes and 24 hours [20], show a high number of 2CSL triple junctions where a CSL boundary $(\leq \Sigma 29, \neq \Sigma 3)$ is connected to a $\Sigma 3$ twin boundary. Data for the effect of grain size (determined by the line intercept method, excluding $\Sigma 3$ twin boundaries) on the average length of $\Sigma 3$ twin and connected CSL $(\leq \Sigma 29, \neq \Sigma 3)$ boundaries is given in Figure $4 \mathrm{a}$, with the as-received and 900/30 microstructures identified.

The connected CSL length is proportional to the twin length, which is shown to be equivalent to the grain size. It is postulated that the observed ductile regions correspond to an area defined by a non-sensitised CSL boundary, which associated with the growth of the twin during recrystallisation (Figure 3b). The data in Figure 4a indicate that the average area of such a region is proportional to the average grain boundary area (i.e. the square of grain size). The tensile failure of these ductile features implies that they have the potential to shield the crack tip from the applied stress. High resolution electron backscatter diffraction (EBSD) of sectioned crack paths (Figure 4b) also suggests that such crack bridges can result from the intersection of the crack with twin-related features. 
These observations indicate that microstructural engineering [5-8], which aims to increase resistance to intergranular stress corrosion crack propagation by increasing the number of twin-related non-sensitised grain boundary segments factors in the microstructure, will also increase the number of features with the potential to form ductile crack bridging ligaments. It is proposed that these ligaments are a significant factor in increasing the resistance of the microstructure to stress corrosion cracking.

\section{Microstructural Effects on SCC Resistance}

A microstructure engineering study was performed to investigate the effects of thermomechanical processing on the parameters likely to improve stress corrosion cracking resistance. The study was based on the proposition that the resistance to stress corrosion cracking develops from the bridges in the crack wake [14]. The frequency of bridge formation depends on the probability of the crack tip encountering a grain boundary triple junction with a resistant grain boundary (i.e. a non-sensitised boundary). These are boundaries with a high degree of coincidence between the crystal lattice orientations of the grains on either side of the boundary, defined using the coincidence site lattice (CSL) model [15]. Twin boundaries ( $\Sigma 3)$ and CSL boundaries with $\Sigma \leq 29$ are commonly regarded as resistant to intergranular corrosion and stress corrosion cracking [5-8]. Crack propagation may also be impeded locally by an unfavourably oriented sensitised boundary. Various percolation-like models [16-19] have been proposed, in which crack arrest is assumed to occur once the crack encounters a resistant feature. The maximum likely crack length, independent of stress, is thus determined by the distribution of resistant triple junctions or grain boundaries.

Our observation of ductile ligaments shows that crack arrest does not necessarily occur when a resistant boundary is encountered. However, the probability of crack bridge formation at a triple junction $(\mathrm{P})$ may be expressed in a similar manner to the percolationlike models, using functions such as Equation 1. Here, $\mathrm{f}_{\mathrm{TJ}(\mathrm{n}-\mathrm{CSL})}$ is the frequency of occurrence of triple junctions with $\mathrm{n}$ resistant boundaries (i.e. non-sensitised CSL, $\Sigma \leq 29$ ) and $\mathrm{f}_{\mathrm{a}}$ and $\mathrm{f}_{\mathrm{b}}$ are geometrical factors (assumed to be 1 and 0.5 respectively), to account for unfavourably oriented sensitised boundaries at the triple junction. The ratio of $\mathrm{f}_{\mathrm{TJ}(1-\mathrm{CSL})}$ to $\mathrm{f}_{\mathrm{TJ}(2-\mathrm{CSL})}$ does not vary significantly over a wide range of microstructures [20], thus the actual values of $f_{a}$ and $f_{b}$ are not critical in the relative ranking of microstructures. It is also recognised that 2-CSL junctions associated with narrow twins may be characterised as 1-CSL junctions by EBSD. The factor P thus expresses the ratio of the number of triple junctions with potential to form crack bridges to the total number available to the crack tip.

\section{Equation 1}

$$
P=\frac{\left(f_{a} f_{T J(2-C S L)}+f_{b} f_{T J(1-C S L)}\right)}{1-f_{T J(3-C S L)}}
$$

For a one-dimensional model, the probability, $\mathrm{X}$, that the crack tip will encounter a resistant triple junction within distance $\mathrm{L}$ can be expressed as Equation 2 [18]. The distance, over which there is a critical probability of bridge formation, say $\mathrm{L}_{99 \%}$ for $\mathrm{X}=99 \%$, will be related to the average distance between crack bridging ligaments on the fracture surface. Since there is a probability that bridging does not occur for a short stress 
corrosion crack nucleated at a surface until the crack length exceeds L99\%, the average crack bridging stress, $\sigma_{b}$, will vary with length for cracks of the order of L99\%. This variation of bridging stress with crack length may have a form such as Equation 3. The crack bridging stress therefore rises and saturates to a maximum value over a length scale determined by $\mathrm{L}_{99 \%}$, which is a function of both the triple junction distribution $(\mathrm{P})$ and the average distance between triple junctions (i.e. grain size). The crack bridging stress acts to shield the crack tip from the applied stress.

\section{Equation 2}

$$
X=1-(1-P)^{2 L / D}
$$

Equation 3

$$
\sigma_{b}=\left(\frac{a / L_{99 \%}-1}{a / L_{99 \%}}\right) \sigma_{b \max } \text { for } a>L_{99 \%}, \sigma_{b}=0 \text { for } a \leq L_{99 \%}
$$

The magnitude of the crack bridging stress induced by the ligaments is difficult to determine using a simple model, since with increasing crack opening displacement relative to the ligament size, the ligaments may deform elastically, plastically or rupture. A constant maximum crack bridging stress, $\sigma_{\mathrm{bmax}}$, is currently assumed for all microstructures. If this is sufficient to arrest or significantly retard crack propagation, then microstructures with the greatest resistance to stress corrosion crack nucleation are predicted to be those in which the bridging stress develops more rapidly with crack length. Such microstructures will have smaller grain size and higher P factors.

The model described above is closely related to percolation-like models for intergranular stress corrosion cracking, in terms of the relative effects of microstructure parameters. However, it removes the implicit assumption in such models that crack arrest occurs when a resistant junction is encountered. This clearly does not occur due to the threedimensional nature of the microstructure, as demonstrated by the $3 \mathrm{D}$ observations of crack bridging ligament formation. The new model includes the effects of applied stress magnitude, and can be applied to short cracks in residual stress gradients to consider the effects of surface preparation and damage on stress corrosion cracking.

The effect of the bridging stress can be represented using a simple linear elastic fracture mechanics model. The magnitude of crack tip shielding available from bridging ligaments is quite low for short cracks and there is an implicit assumption that stress corrosion cracking occurs with very low values of crack tip strain [21]. Crack propagation occurs if the net crack tip stress intensity factor is greater than a short crack

threshold $\mathrm{K}_{1 \mathrm{SCC}}$, which is assumed to be small ( 0.1 MPa $\left.\sqrt{\mathrm{m}}\right)$ [14]. The critical threshold stress, $\sigma_{\text {th }}$, can then be calculated as the remote applied stress necessary to increase the net crack tip stress intensity factor above $\mathrm{K}_{1 \mathrm{SCC}}$ (Equation 4 ). The variation of threshold stress with crack length is illustrated in Figure 5 for two different microstructures. A semi-circular crack, radius a, is assumed. 


\section{Equation 4}

$$
\sigma_{\mathrm{th}}=\frac{\sqrt{2 \pi}\left(K_{s h}+K_{I S C C}\right)}{\sqrt{a}} \text { where } K_{s h}=\sigma_{b} \sqrt{a / 2 \pi}
$$

The model parameters for the two test microstructures (before and after a $30 \%$ strain followed by a 30 minute anneal at $900^{\circ} \mathrm{C}$ ) are summarised in Table 3. These two microstructures have quite similar $P$ factors, but differ significantly in grain size. All data was obtained using a constant EBSD sampling step size of $5 \mu \mathrm{m}$. This large step size was selected to obtain consistent data over a wide range of microstructures, and measurements using smaller step sizes $(>1 \mu \mathrm{m})$ have shown that although the number of triple junctions is affected by the step size, the factor $P$ is insensitive to step size. However, the grain size was found to be overestimated when the step size was larger than $20 \%$ of the grain size [20]. This is consistent with EBSD observations in other microstructures [23], from which the measured grain size of the 900/30 microstructure is thus expected to be an overestimate, by approximately $30 \%$, relative to the as-received grain size.

In order to assess the effect of microstructure engineering on crack growth, crack propagation tests were performed on the two test microstructures using the double-beambent specimen geometry described in the experimental section. Typical crack growth results after 144 hours at 200MPa are given in Figure 6 for the microstructure processed at $900^{\circ} \mathrm{C}$ and annealed for 30 minutes (900/30), compared to the as-received microstructure. When considering the results it is important to note that X-ray diffraction (XRD) analysis demonstrated that the surface residual stresses introduced by sample preparation were not significant, having a magnitude of less than $50 \mathrm{MPa}$. The applied stress was also monitored during the tests using XRD, and stress relaxation was not observed. The effects of test duration and test reproducibility were also investigated. The crack populations were stable in each microstructure, demonstrating that measurable crack propagation has ceased within the duration of the test. Further details of these tests for materials having a range of microstructures are described elsewhere [20].

Simple inspection of the data summarised in Figure 6 shows that the 900/30 microstructure has the greater resistance to stress corrosion cracking, developing a population of significantly shorter cracks than the as-received microstructure. The parameter $\mathrm{y}$, which is derived from the rank of the crack size in the ordered series of $\mathrm{n}$ observations [25], describes the probability of occurrence of a crack of a given size. This provides a convenient method of describing the population of observed cracks, with comparisons in the maximum likely crack length in the test specimen being made at equivalent values of $y$. The observed difference in maximum crack size is consistent with the relative rates of development of crack bridging predicted for the two microstructures, as defined by the difference in $\mathrm{L}_{99 \%}$ (Table 3). The predicted variation of threshold stress with crack length is given in Figure 5, assuming a maximum crack bridging stresses of $300 \mathrm{MPa}$ in both microstructures. The proposed model therefore appears reasonable, although it predicts a less significant difference between the two microstructures than is observed. This may be partly attributed in part to the overestimate in the grain size of the 900/30 microstructure. The predicted effect of reducing the measured grain size by $30 \%$ is shown in Figure 5. Non-random connectivity of susceptible boundaries may also be a factor. The data for the as-received microstructure also does not fit the extreme value 
distribution well. This indicates that there may be two populations of cracks present. This might be explained by loss of significance of the crack bridging mechanism at longer crack lengths as the crack opening displacements increase.

Current work aims to investigate the crack propagation behaviour in a range of microstructures to determine whether the maximum crack bridging stress is affected by significant variations in P. The effects of non-random connectivity of susceptible boundaries and near-surface residual stresses are also being investigated.

\section{High Temperature Crack Propagation Behaviour}

Intergranular stress corrosion cracking is a problem in pressurised water cooling systems operating at high temperature. Crack initiation was found to be very difficult in $0.01 \mathrm{M}$ $\mathrm{Na}_{2} \mathrm{SO}_{4}$ electrolyte at $250^{\circ} \mathrm{C}$ in short times under static load. However intergranular stress corrosion cracking did propagate under autoclave conditions after an initial exposure of electropolished samples to tetrathionate solution $(\mathrm{pH} 2.5)$ for 4 hours at room temperature to initiate intergranular corrosion damage at the surface (

Figure 7a). The high temperature fracture surface was similar to the room temperature behaviour, with ductile ligament formation (

Figure 7b). There was also evidence for some transgranular cracking (

Figure 7c). Crack bridging therefore occurs, and microstructure engineering has potential to influence stress corrosion cracking resistance.

The effects of test duration on the depth of stress corrosion crack (SCC) penetration and the depth of the intergranular corrosion damage (IGC) are shown in Figure 8 for the asreceived microstructure. The extreme value distribution for the crack population has been determined.

The data in Figure 8 shows that the maximum depth of intergranular corrosion, which initiated cracking, is not affected by test duration, whereas the maximum depth of stress corrosion cracking increases with time. This data also suggests that some shorter stress corrosion cracks and intergranular corrosion damage are not clearly distinguished, and there is thus some overlap of the two measured populations. These preliminary results demonstrate that crack propagation rates for short stress corrosion cracks can be determined from these static tests. Measurements of the effects of test duration and stress on the crack population can therefore be employed to investigate the effects of microstructure engineering on stress corrosion crack propagation resistance.

Work is in progress to investigate the effects of microstructure in this environment, and to confirm whether transgranular cracking in the autoclave environment is associated with the plastically strained crack bridging ligaments. This would have a potentially detrimental effect on the crack shielding mechanism and stress corrosion cracking resistance.

\section{Three Dimensional Modelling of Crack Propagation}

While simple models of crack propagation such as that given above provide important insights into stress corrosion cracking, the observation of ductile ligaments due to crack 
bridging, and the demonstrable effects of microstructure engineering on crack propagation behaviour provide a mechanistic basis for $2 \mathrm{D}$ and $3 \mathrm{D}$ models for intergranular crack propagation. The aim is to provide a tool for theoretical investigations of the interaction between multiple cracks and the influence of residual stress gradients. Such a model will also provide a better understanding of the elastic/plastic behaviour of crack bridging ligaments and their effect of the crack shielding stresses. A simple 2D model for intergranular crack percolation with crack bridging has been developed, and is described elsewhere [27]. The 3D model is described briefly below.

At the physical level, the geometry of the microstructure can be represented by a regular tessellation of space into identical cells. As in previous works on percolation modelling of three dimensional intergranular cracking, e.g. [15-19, 28], the unit cell is chosen to be a truncated octahedron, known also as tetrakaidecahedron or mecon. This is a polyhedron having six square and eight regular hexagonal faces (Figure 9). The unit cell diameter, $D$, is the edge of the cell bounding cube. This may be considered as a measure of the average grain size. The faces common to neighbouring cells represent grain boundaries, which are classified as either resistant or sensitive to intergranular fracture. Susceptible boundaries are assumed to fail at a very small strain, $\varepsilon_{f}$, and without significant inelastic deformations in their vicinity, when encountered by a propagating crack. Resistant boundaries are assumed to fail in a ductile mode after a significant amount of accumulated inelastic strain. These properties are consistent with the observed failure mechanisms (e.g. Figure 2 and Figure 3).

At the computational level, a discrete representation of the assembly of mecons is employed. This is done in view of the subsequent finite element formulation of the crack propagation problem. In the discrete representation, each mecon is substituted by a node at its central point and the mecon's fourteen faces are substituted by beam elements linking it to the central points of the neighbouring mecons. This is shown schematically in Figure 9, where cylinders represent the beam elements. This leads to a significant reduction of the nodes and elements in a model and hence of the computational effort, which is crucial for three dimensional problems. The element cross sections were varied to ensure that the assembly behaved like a solid under the same deformation when subjected to tensile deformation in the elastic range.

The modelled assembly contains 30000 grains, which form 198310 internal grain boundaries (modelled by 30000 nodes and 198310 beam elements) in the finite element model. A small intergranular pre-crack is introduced by removing three beam elements. The elements are assumed be elastic-plastic with linear isotropic hardening. The modulus of elasticity $E=200 \mathrm{GPa}$ and Poisson's ratio $v=0.3$. In the current formulation, the resistant elements have a yield stress $\sigma_{y}=200 \mathrm{MPa}$ with yield strain $\varepsilon_{y}=10^{-3}$ and ultimate strength $\sigma_{u}=400 \mathrm{MPa}$ at ultimate strain $\varepsilon_{u}=0.1$. Elements representing susceptible boundaries are assumed to fail at strain $\varepsilon_{f}<\varepsilon_{y}$ (Figure 10). The two types of behaviour are randomly distributed among the elements, depending on a given fraction of resistant boundaries, $f$. The load is symmetric and applied via prescribed displacements which introduces a homogeneous strain in the assembly $\varepsilon_{\infty}=5 \times 10^{-4}$, equivalent to a homogeneous remotely applied stress $\sigma_{\infty} \approx 0.5 \sigma_{y}$. 
The modelling of crack propagation is handled by two separate software components. Equilibrium is found using the commercial finite element program ABAQUS [30]. The solution is then analysed by a program developed in-house, which examines all elements in contact with the crack surface. Element conditions are compared against their failure criteria, and at most one boundary, being either susceptible or resistant, is allowed to fail per step. Equilibrium is then re-established using ABAQUS, and the analysis is repeated until crack propagation ceases or the simulation is terminated.

Simulations have been performed for different fractions of resistant boundaries. Figure 11 illustrates the crack configuration after 200 steps of growth, i.e. approximately 200 failed boundaries, in a material with $30 \%$ resistant boundaries. A number of crack bridges are clearly identified along the crack surface. This demonstrates the ability of the model to simulate $3 \mathrm{D}$ crack propagation.

Current work in progress aims to quantify the effects of crack bridging on the crack shielding in the 3D model, and to study the effects of residual stress gradients and crack interactions. Further refinement of the model using experimental results will be necessary before it becomes a useful predictive tool.

\section{Summary}

- Observations of intergranular stress corrosion cracking in sensitised stainless steel show that resistant grain boundaries can bring about crack bridging. It is proposed that these bridges provide resistance to the propagation of short stress corrosion cracks. The development of these bridges and thereby this resistance is affected by the grain boundary triple junction distribution and the grain size.

- This proposition is supported by experimental data for the effect of microstructure engineering on crack propagation resistance. The level of resistance provided by this mechanism may vary with the environment. Transgranular cracking may occur in high temperature/pressure conditions for example.

- The observations provide a mechanistic basis for a new three-dimensional computational model of short stress corrosion crack propagation. Preliminary results demonstrate that the 3D model captures experimentally observed behaviour.

\section{Acknowledgements}

We would like to thank J.-Y. Buffiere and E. Maire of INSA, Lyon for the use of the in situ loading stage and P. Cloetens for help on ID19 at the ESRF. PJW acknowledges support of a Royal society-Wolfson Merit Award. The support of RR plc for DE, PW and APJ is gratefully acknowledged, as the support of TJM and NS by BNFL through their Materials Performance Centre, a University Research Alliance. 


\section{References}

1. Scott P.M., Corrosion, 56, 771-782, 2000.

2. Newman R.C., Corrosion, 57, 1030-1041, 2001.

3. Akashi M., Nakayama G, Proc. 9th International Conference on Environmental Degradation of Materials in Nuclear Power Systems, Minerals, Metals \& Materials Soc., Warrendale, PA., 389-396. (1999).

4. Christman T.K., Corrosion, 46450-453, 1990.

5. Kim S.H., Erb U., Aust K.T., Palumbo G., Scripta Mater., 44, 835-839, 2001.

6. Palumbo G., Aust K.T., Can. Metall.1 Q., 34, 165-173, 1995.

7. Kokawa H., Shimada M., Sato Y.S., JOM-J. Min. Met. \& Mater. Soc., 52, 34-37, 2000.

8. Gertsman V.Y., Bruemmer S.M., Acta Mater., 49 1589-1598, 2001

9. Ludwig, W., Buffiere, J.Y., Savelli, S., Cloetens, P., Acta Mater. 51, 585-598, 2003.

10. Baruchel, J., Cloetens, P., Hartwig, J., Ludwig, W., Mancini, L., Pernot, P., Schlenker, M., 7,196-201, 2000

11. Marrow, T.J., Withers, P.J., Buffiere, J.Y., Newman, R., Engelberg, D., Babout, L., Johnson, G., http://ftp.esrf.fr/pub/UserReports/25143_A.pdf. ESRF Experimental report: me577, 2003.

12. Marrow TJ, Babout L, Connolly BJ, Engelberg D, Johnson G, Buffiere JY, Withers PJ, Newman RC, Environment-Induced Cracking of Metals (EICM-2), Banff, Canada, 2004.

13. Mercury Computer Systems. http://www.amiravis.com. Website, 2004.

14. Engelberg D, Marrow TJ, Newman RC and Babout L, Environment-Induced Cracking of Metals (EICM-2), Banff, Canada, 2004.

15. Grimmer, H., Bollmann, W., Warrington, D.H. Acta Cryst. A30, 197-207, 1974.

16. Lehockey EM, Palumbo G, Lin P, Brennenstuhl AM, Scripta Mater. 36, 12111218, 1997.

17. Palumbo G, King PJ, Aust KT, Erb U, Lichtenberger PC, Scripta Metall. Mater. 25, 1775-1780, 1991.

18. Gertsman VY, Tangri K, Valiev RZ, Acta Metall. Mater. 42, 1785-1804, 1994.

19. Lehockey EM, Brennenstuhl AM, Thompson I, Corr. Sci. 46 (10): 2383-2404, 2004.

20. Engelberg D, PhD thesis, Grain Boundary Engineering for Intergranular Stress Corrosion Resistance in Austenitic Stainless Steel, University of Manchester, 2005. 
21. Thomas L.E., Bruemmer S.M., Corrosion 56, 572-587, 2000.

22. Brandon DG, Acta Metall. 14, 1479-1484, 1966

23. Humphreys, F.J., Journal of Materials Science 36, 3833 - 3854, 2001

24. ASTM G-39: Standard Practice for Preparation and Use of Bent-Beam StressCorrosion Test Specimens, 1999.

25. Gumbel EJ, Statistics of Extremes, Columbia University Press, 1958.

26. Kokawa M, Introduction to Life Prediction of Industrial Plant Materials Application of Extreme Value Statistical Method for Corrosion Analysis, Allerton Press, 1994.

27. Jivkov AP, Stevens NPC and Marrow TJ, ElectroCorr 05, 2005.

28. Lim LC, Watanabe T, Acta Metall. Mater. 38 (12): 2507-2516, 1990.

29. Garbacz A, Grabski MW, Acta Metall. Mater. 41 (2): 469-473, 1993.

30. ABAQUS User's Manual, Version 6.4, Abaqus Inc., 2004. 
Table 1: Chemical composition (wt.\%).

\begin{tabular}{|c|c|c|c|c|c|c|c|c|c|}
\hline UNS & $\mathbf{F e}$ & $\mathbf{C r i}$ & $\mathbf{N i}$ & $\mathbf{C}$ & $\mathbf{M n}$ & $\mathbf{P}$ & $\mathbf{S}$ & $\mathbf{S i}$ & $\mathbf{N}$ \\
\hline S30400 & Bal. & 18.15 & 8.60 & 0.055 & 1.38 & 0.032 & 0.005 & 0.45 & 0.038 \\
\hline S30200 & Bal. & 18.14 & 8.60 & 0.070 & 1.25 & 0.025 & 0.003 & 0.40 & n.a. \\
\hline
\end{tabular}


Table 2: Summary of microstructure parameters for grain boundary and triple junction distribution for the as-received microstructure and after a $30 \%$ strain, $900^{\circ} \mathrm{C}$ anneal for 30 minutes $(900 / 30)$.

\begin{tabular}{|l|c|c|c|c|}
\hline Structure & $\begin{array}{c}\text { Grain Size, } \\
\mathrm{D}(\mu \mathrm{m}) \\
\text { (including } \\
\text { twins) }\end{array}$ & $\begin{array}{c}\text { Grain Size, } \\
\mathrm{D}(\mu \mathrm{m}) \\
\text { (excluding } \\
\text { twins) }\end{array}$ & $\begin{array}{c}\text { Fraction of } \\
\text { CSL } \\
\text { Boundaries } \\
(\%)\end{array}$ & $\begin{array}{c}\text { Fraction of } \\
\Sigma 3 \\
\text { Boundaries } \\
(\%)\end{array}$ \\
\hline As-Rec & $20.6 \pm 3.1$ & $26.5 \pm 4.5$ & $35.2 \pm 3.2$ & $21.8 \pm 0.7$ \\
\hline $900 / 30$ & $9.5 \pm 0.2$ & $11.4 \pm 0.3$ & $27.2 \pm 0.8$ & $13.3 \pm 0.2$ \\
\hline
\end{tabular}


Table 3: Summary of microstructure model parameters for grain boundary and triple junction distribution for the as-received microstructure and after $30 \%$ strain, $900^{\circ} \mathrm{C}$ anneal for 30 minutes (900/30). Average and range calculated from three measurements. The parameter L99\% was determined from the grain size (including twins) (Table 2)

\begin{tabular}{|l|c|c|c|c|c|c|}
\hline \multirow{2}{*}{ Structure } & \multirow{2}{*}{$\mathrm{P}$} & \multicolumn{4}{|c|}{ Triple Junction Distribution (\%) } & \\
\cline { 3 - 7 } & & $\mathrm{F}_{(0-\mathrm{CSL})}$ & $\mathrm{F}_{(1-\mathrm{CSL})}$ & $\mathrm{F}_{(2-\mathrm{CSL})}$ & $\mathrm{F}_{(3-\mathrm{CSL})}$ & \\
\hline As-Rec & $0.43 \pm 0.01$ & $27.8 \pm 1.7$ & $52.4 \pm 1.0$ & $13.8 \pm 1.1$ & $5.9 \pm 3.1$ & $84.4 \pm 12.7$ \\
\hline $900 / 30$ & $0.34 \pm 0.01$ & $43.0 \pm 1.0$ & $43.8 \pm 1.0$ & $11.6 \pm 0.8$ & $1.6 \pm 0.3$ & $52.6 \pm 1.1$ \\
\hline
\end{tabular}




\section{Figure Captions}

Figure 1: Unloaded stainless steel wire sample in the environmental cell. The inner Perspex tube contains the $0.15 \mathrm{M}$ potassium tetrathionate solution, the outer tube acts as the load column. Both are transparent to X-rays. The CCD imaging detector is to the right of the image.

Figure 2: Tomography data from in-situ stress corrosion cracking experiments $(\mathrm{pH} 2$ tetrathionate solution, sensitised 302 stainless steel). (a-c) reconstructed longitudinal slices (yz plane) of the same region of interest at three different stages in the stress corrosion test. (d) 3D iso-surface surface rendering, viewed from within the crack, of a crack bridging ligament (indicated by an arrow).

Figure 3: a) An example of ductile ligaments, observed on intergranular facets from the fractograph of the failed wire, b) schematic of the grain shown in (a) with $\Sigma 3$ twin grain boundaries normal to the page forming a triangular corner twin and a lamella twin. The shaded regions, which correspond to the ductile regions in (a) are postulated to be CSL segments of the grain boundary formed by the twin growth.

Figure 4: (a) Effect of grain size on twin length and connected CSL boundary length in a a range of thermo-mechanically processed microstructures $\left(30 \%\right.$ strain, anneal at $900^{\circ} \mathrm{C}$ to $1100^{\circ}$ for 2 minutes to 24 hours). Data for the as-received and 900/30 microstructures are highlighted. (b) EBSD map of a metallographic section of a stress corrosion crack in the as-received microstructure $(\mathrm{pH} 2.5$ tetrathionate solution, sensitised 304 stainless steel). Local crack arrests are 1-CSL and 2-CSL triple junctions are circled. The crack is shown in grey, the twin and CSL boundaries in pale grey, and the high angle grain boundaries in black.

Figure 5: Predicted development of crack propagation threshold stress with increasing crack length for the $30 \% / 900^{\circ} \mathrm{C} / 30 \mathrm{~min}$ and as-received test microstructures, compared with an applied stress of $200 \mathrm{MPa}$. The effect of accounting for the expected $30 \%$ overestimate in the grain size of the 30\%900/30 microstructure is also shown (900/30 reduced grain size). The maximum crack bridging stress has been taken to be $300 \mathrm{MPa}$ for both microstructures. The behaviour at very short crack lengths $(<30 \mu \mathrm{m})$ is an artefact of the simple linear elastic fracture mechanics model, which is not considered to be valid for crack lengths of the order of 1 to 2 grain diameters.

Figure 6: Crack population data, expressed as the reduced variant (y) as a function of the observed crack length for the 30\%/900/30 and as-received microstructures tested under an applied stress of $200 \mathrm{MPa}$ for 144 hours. Solid lines are least square best fits to the data. Dashed lines are the $95 \%$ confidence limits.

Figure 7: Crack propagation in the high temperature autoclave environment (a) Metallographic section of intergranular stress corrosion crack (propagating from left to right), (b) Ductile ligament on intergranular fracture surface, (c) Transgranular cracking (indicated with arrow)

Figure 8: Effects of test duration on the observed populations of stress corrosion cracking (SCC) and intergranular corrosion damage (IGC) in high temperature autoclave tests in 
as-received, fully sensitised 304 stainless steel. Solid lines are least square best fits to the data. Dashed lines are the $95 \%$ confidence limits.

Figure 9: Physical model of a grain (mecon) for the three-dimensional polycrystalline model and its discrete counterpart using beams.

Figure 10: Schematic illustration of behaviour of susceptible and resistant boundaries employed in the three-dimensional model.

Figure 11: Three-dimensional crack generated after 200 crack growth steps, showing bridges. The fraction of resistant boundaries was 30\%. Only the cracked boundaries are shown - some bridging ligaments are evident as 'holes' in the crack. 


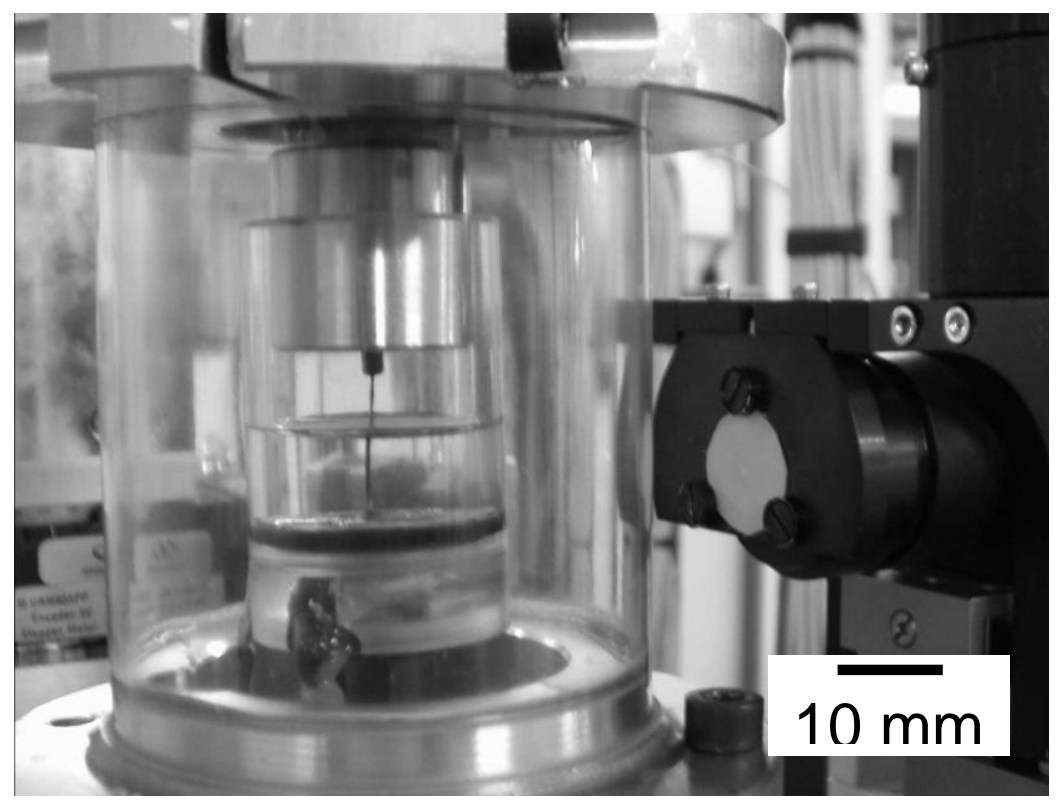

Figure 1 
(a)

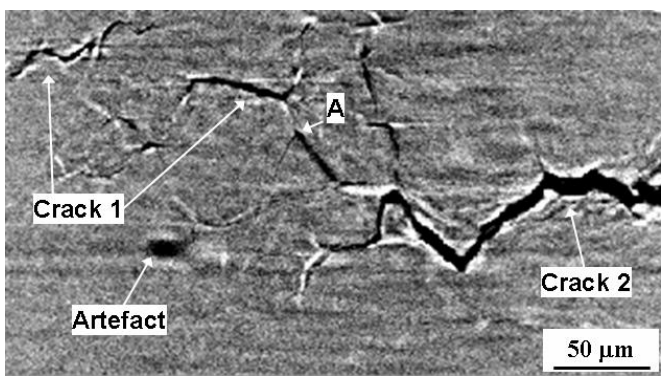

(b)

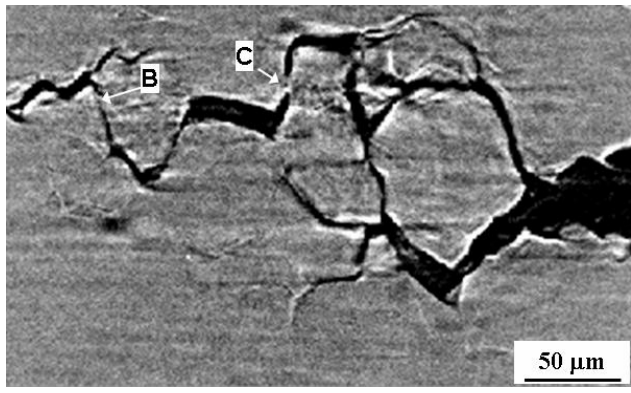

(c)

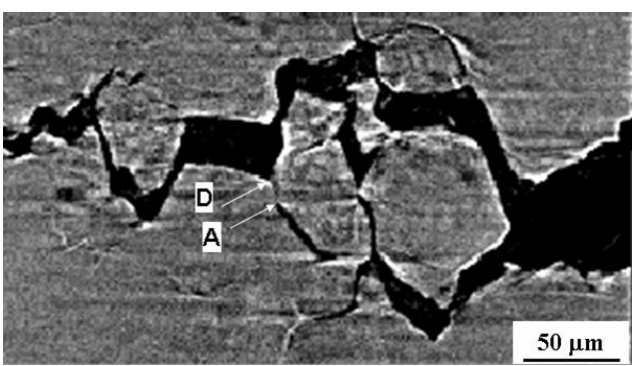

(d)

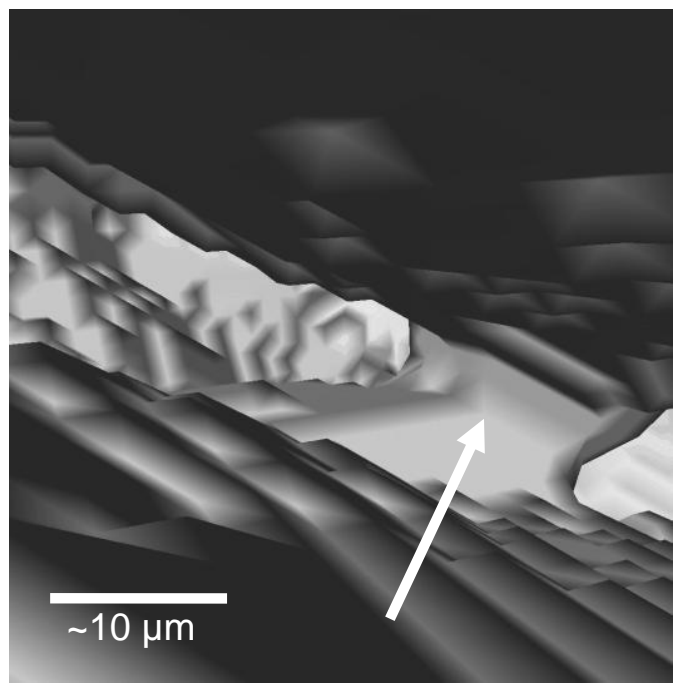

Figure 2 
(a)

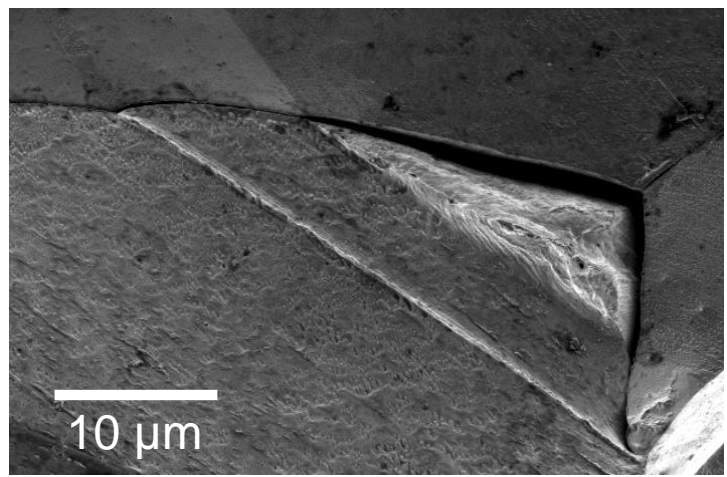

(b)

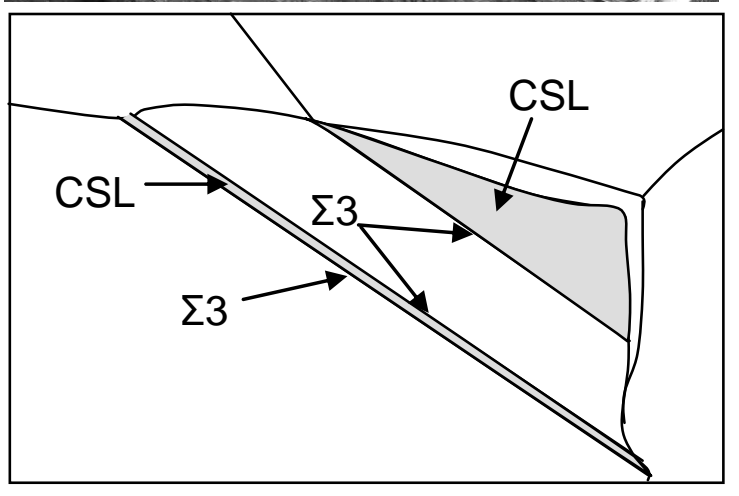

Figure 3 


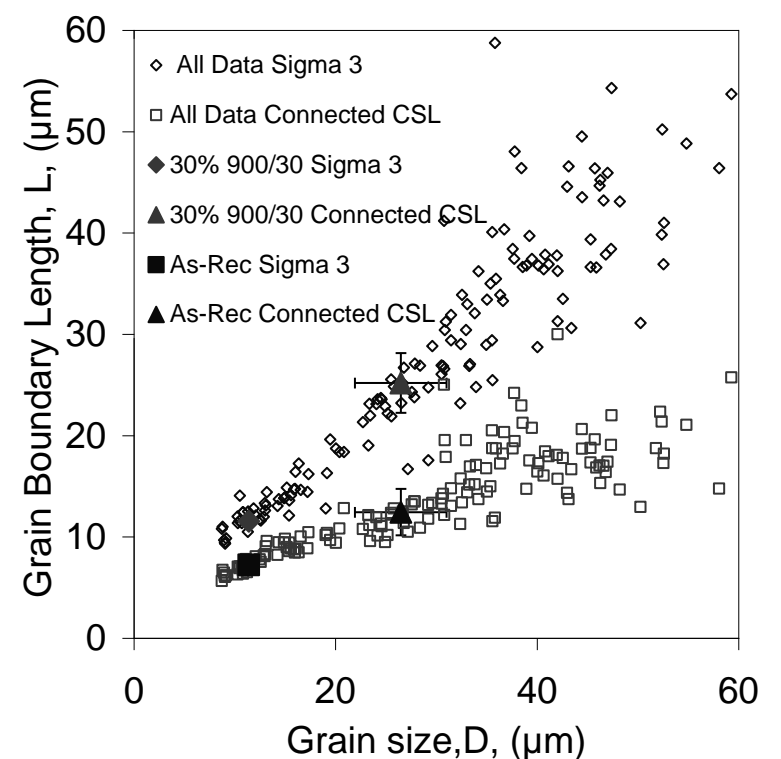

(a)

$$
\text { Grain size,D, }(\mu \mathrm{m})
$$

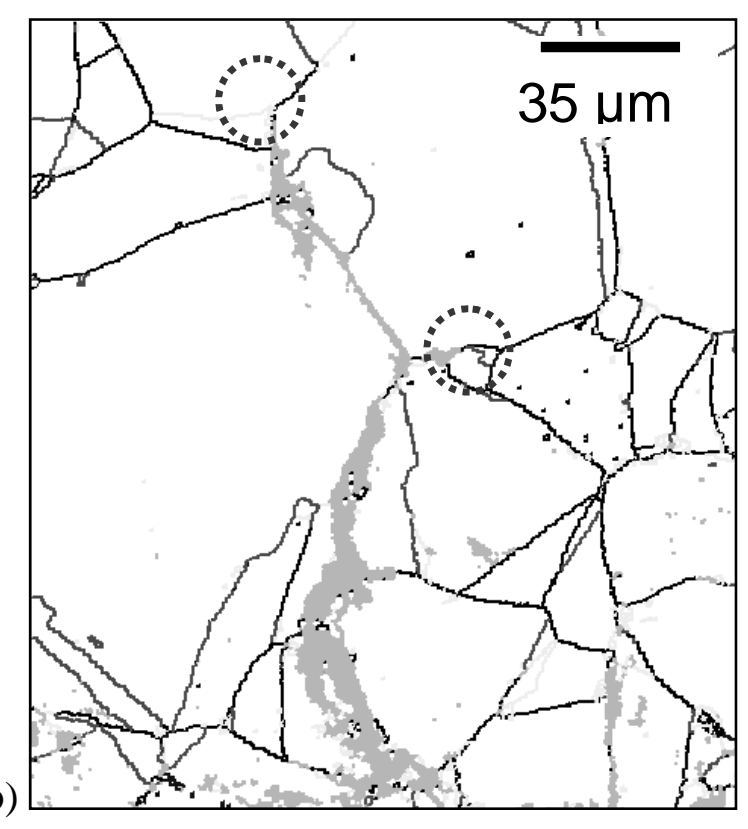

Figure 4 


$$
\begin{aligned}
& \text { - . - Applied Stress } \\
& \text { - Threshold Stress 900/30 } \\
& \text { - - - Threshold Stress 900/30 (reduced grain size) } \\
& \text { - - - Threshold Stress As-Rec }
\end{aligned}
$$

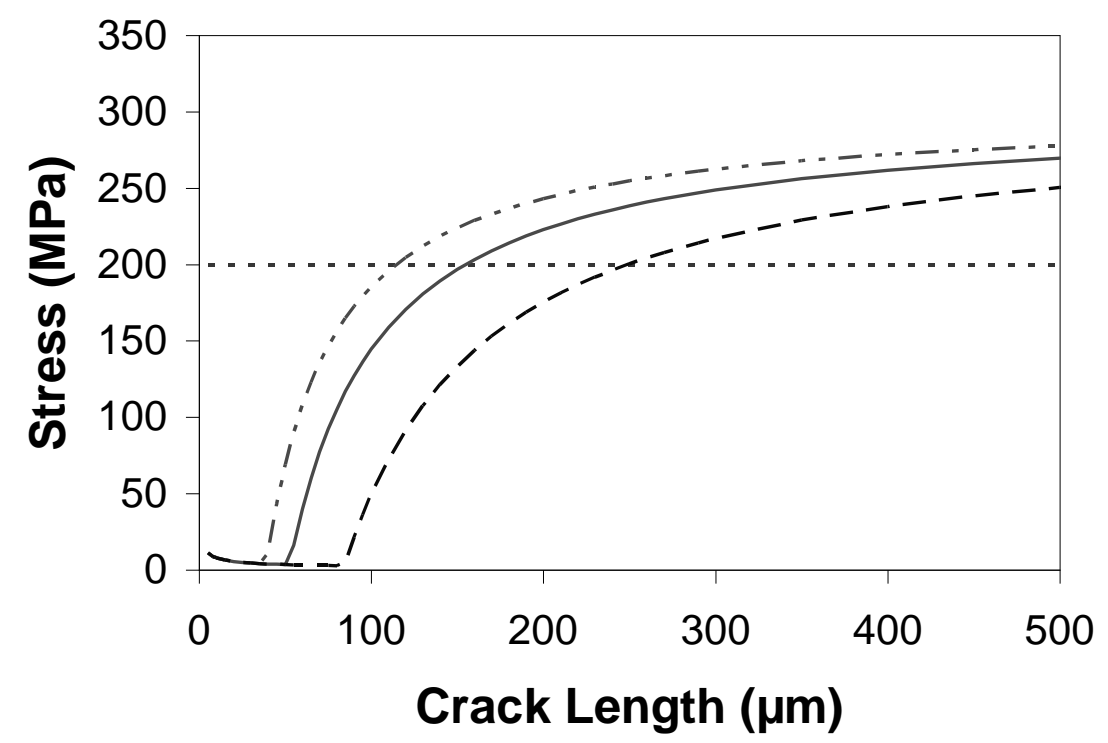

Figure 5 


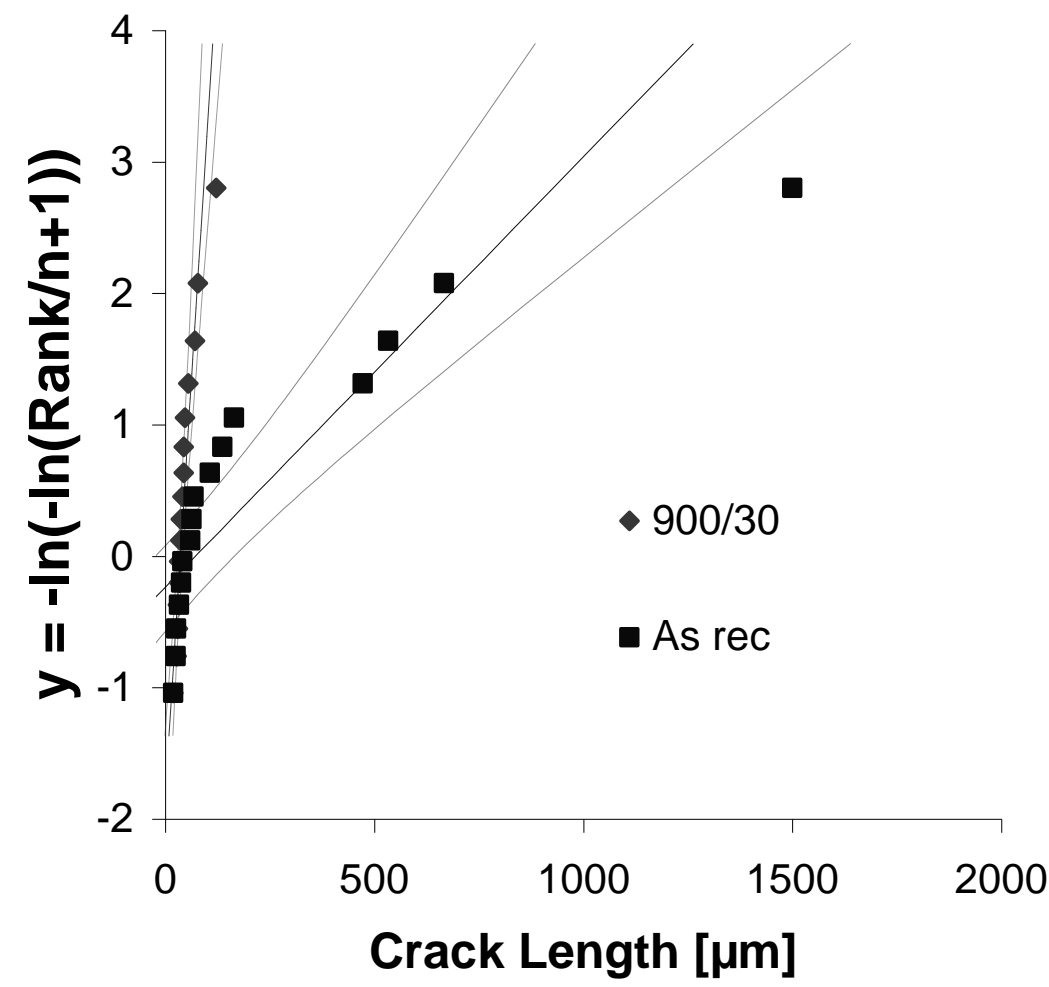

Figure 6 


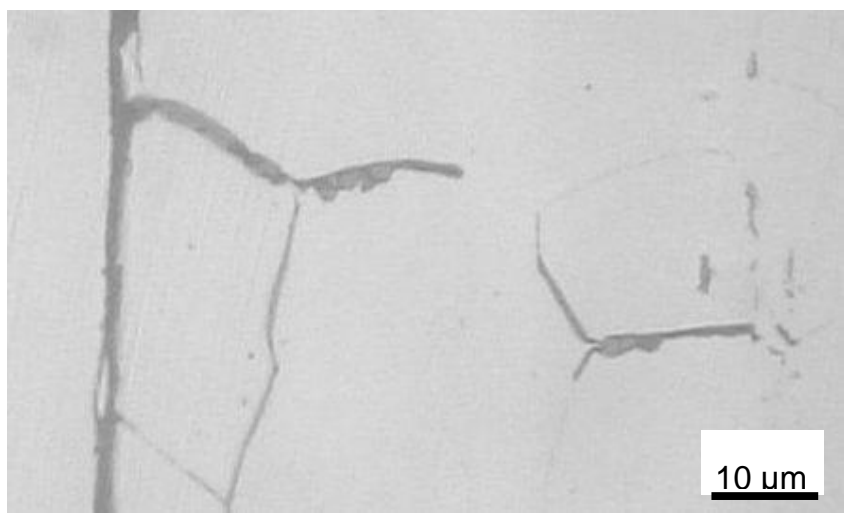

Figure 7(a)

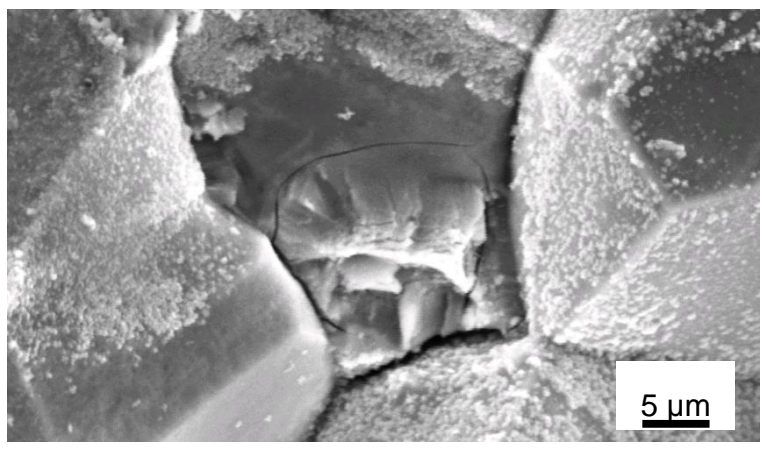

Figure $7 b$

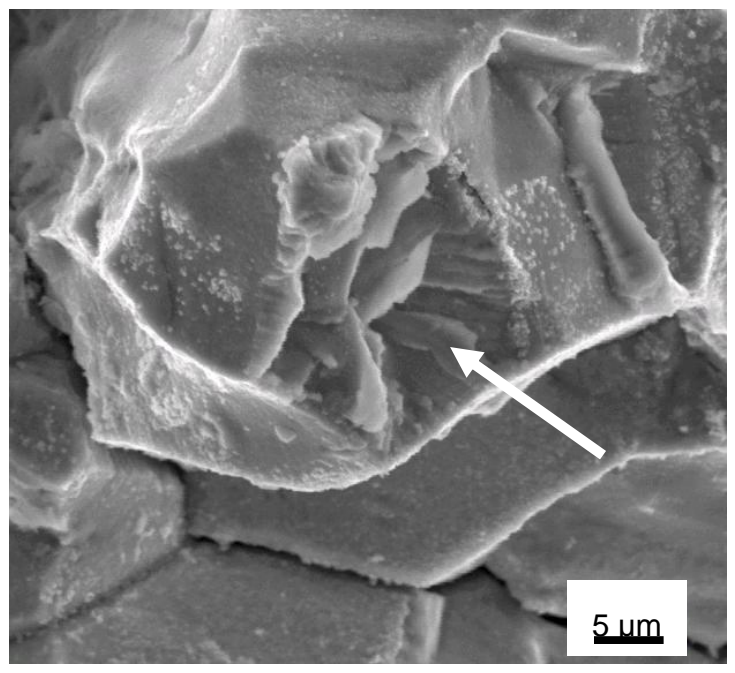

Figure 7c 


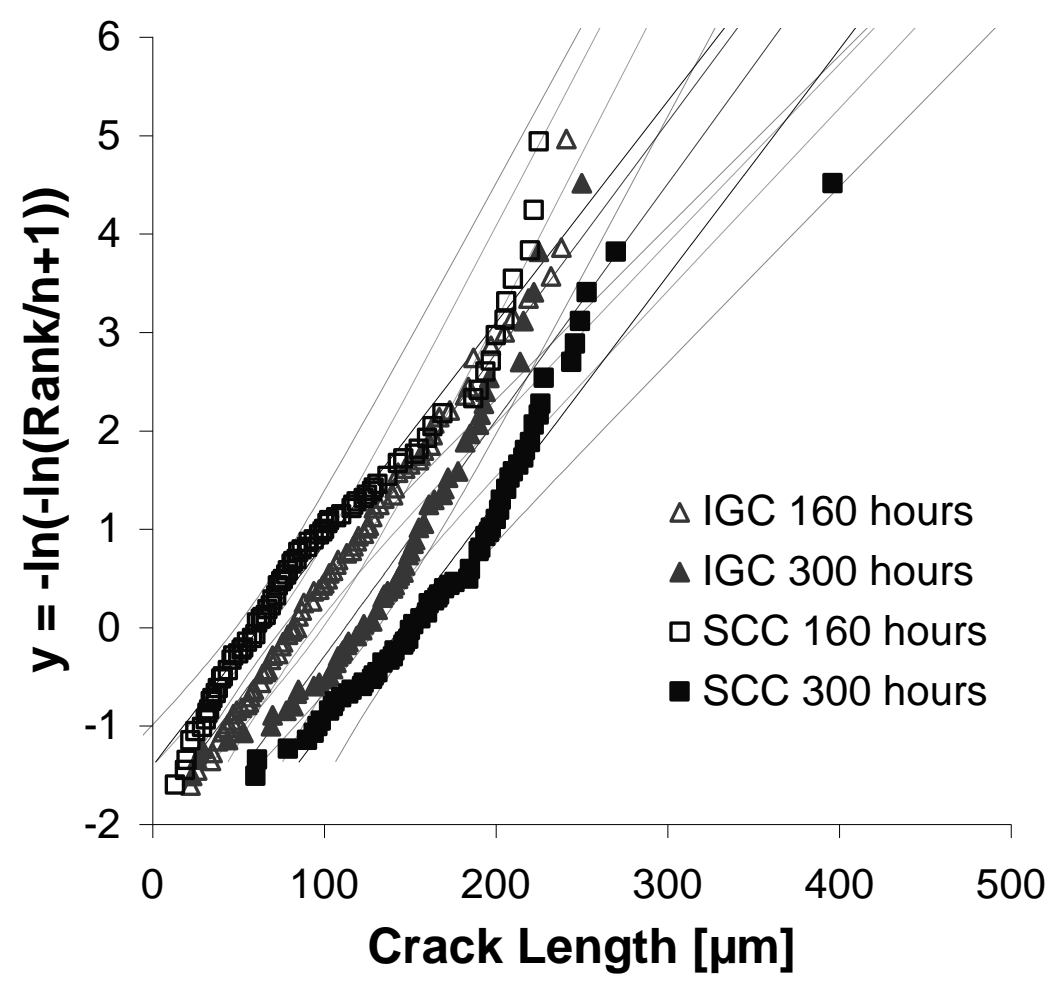

Figure 8 


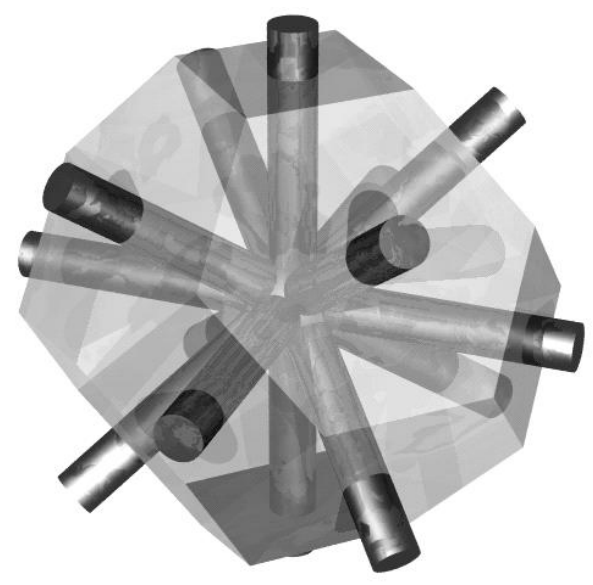

Figure 9 


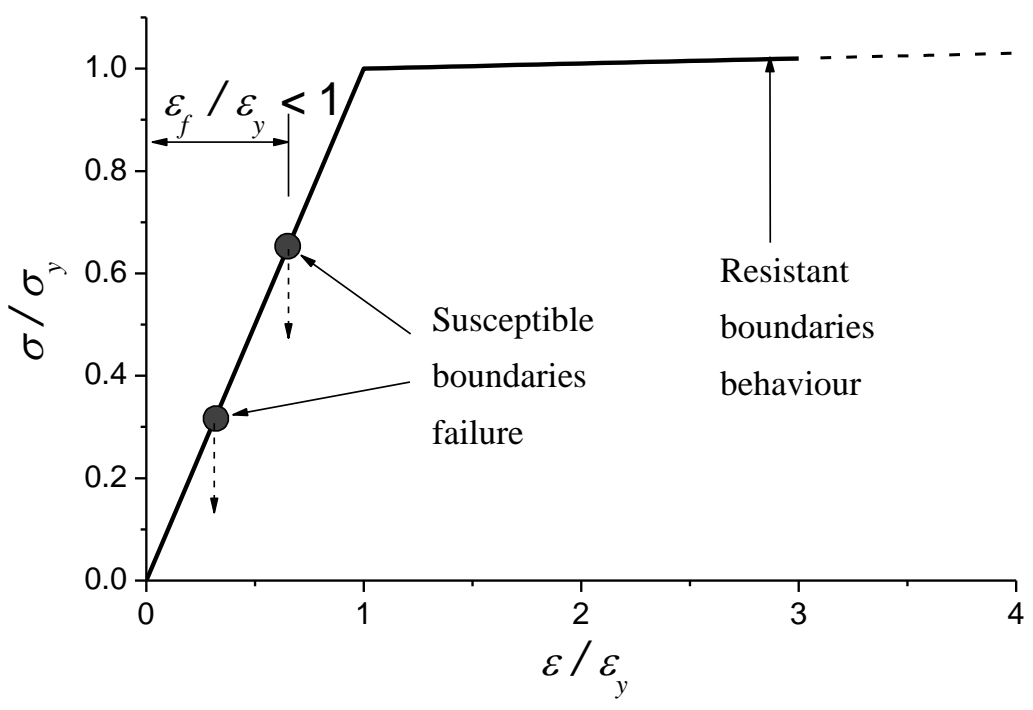

Figure 10 


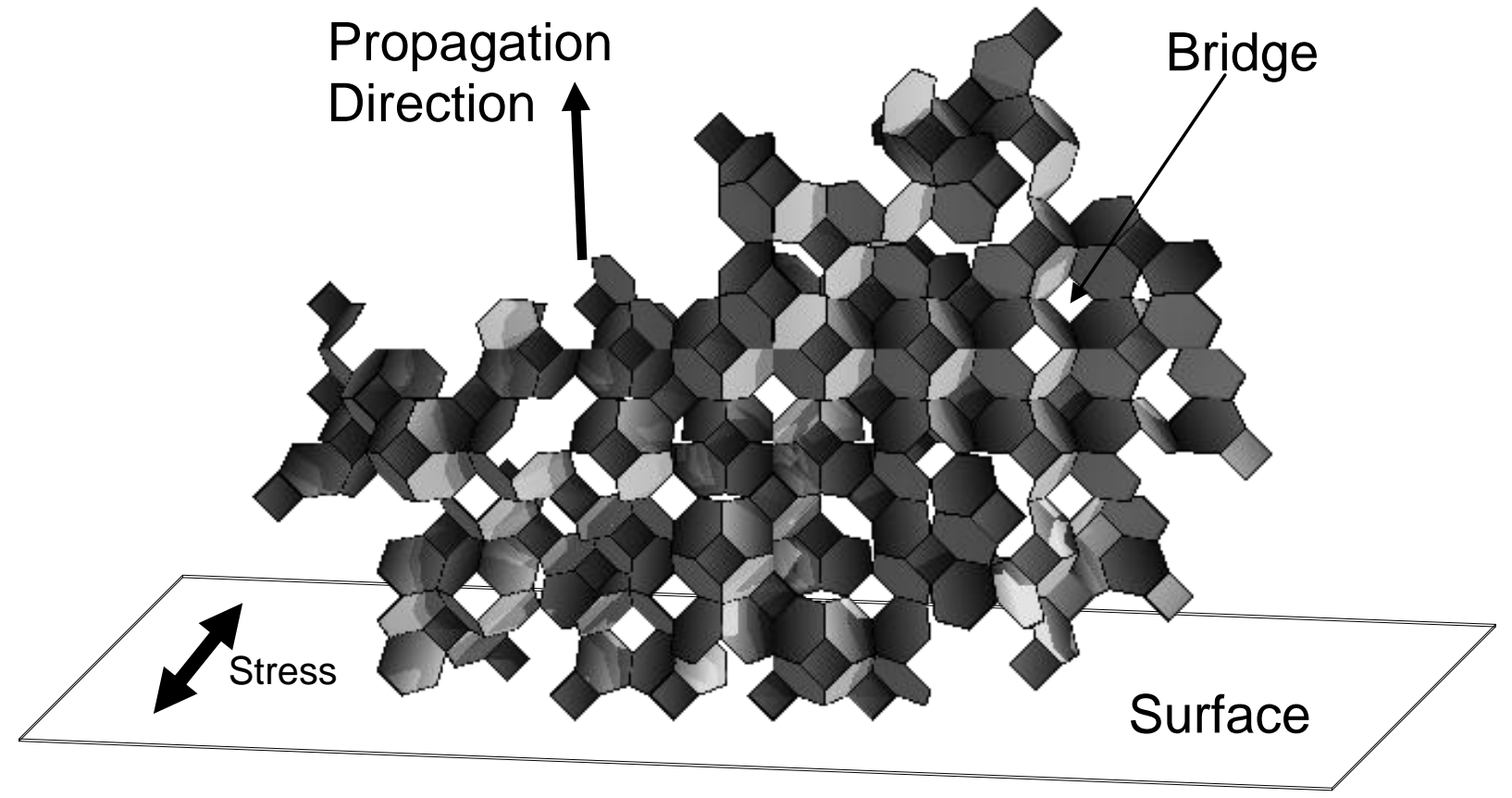

Figure 11 